\title{
ANATOMICAL VARIATIONS RELATED TO POSITION OF APPENDIX
}

\author{
Yashwant R. Lamture1, Balaji Salunke ${ }^{2}$
}

1 Professor, Department of General Surgery, JNMC, Wardha, Maharashtra, India.

${ }^{2}$ Assistant Professor, Department of General Surgery, JNMC, Wardha, Maharashtra, India.

\section{BACKGROUND}

\section{ABSTRACT}

Appendix may be placed in different positions, but the base of appendix is connected to the cecum. Based on the variations in the situations, appendix is classified into six positions: retrocecal, pelvic, subcecal, paraileal, retroileal and subhepatic.

Aim- To study the variation in the anatomical features, length and external diameter of appendix and its association with age and sex in the Indian population.

\section{MATERIALS AND METHODS}

This descriptive study was conducted on a total of 418 cases, anatomical location of appendix was recorded, and length of vermiform appendix was measured with nylon thread from root to tip of appendix. Thread's length was measured by vernier caliper. External diameter was measured by vernier caliper at the maximum external diameter of the appendix.

\section{RESULTS}

Around 418 subjects were included in the study, consisting of 251 (60.05) males and 167 (39.95) females. Clinically diagnosed acute appendicitis cases were subjected to thorough clinical examination, lab investigations, USG abdomen and appendiceal specimen was sent for histopathological examination after surgery. Anatomical locations of the appendix was as follows: Retrocecal in 111 individuals (55.5\%), Pelvic in 47 individuals (23.5\%), Retroileal in 18 individuals (9.0\%), Subcecal in 13 individuals (6.5\%), Paracecal in 10 individuals (5.0\%) and Subhepatic in 1 individual (0.5\%). A significant association was found between the appendix length and different age groups. The average length of appendix was $55 \mathrm{~mm}$ for men and $51 \mathrm{~mm}$ for women. The average external diameter of appendix was $73 \mathrm{~mm}$ for men and $65 \mathrm{~mm}$ for women.

\section{CONCLUSION}

Retrocecal appendix has symptoms of upper urinary tract infection due to irritation of the adjacent ureter. In pelvic position, pain may be felt when the thigh is flexed and medially rotated as the obturator internus is stretched. Pelvic appendix may irritate the bladder or rectum causing suprapubic pain, pain with urination or feeling of a need to defecate.

\section{KEY WORDS}

Appendicitis, Mesoappendix, Retrocecal, Vermiform.

HOW TO CITE THIS ARTICLE: Lamture YR, Salunke B. Anatomical variations related to position of appendix. J. Evolution Med. Dent. Sci. 2018;7(46):5030-5033, DOI: 10.14260/jemds/2018/1119

\section{BACKGROUND}

The classical signs and symptoms of acute appendicitis were first reported by Reginald Haber Fitz (America) in 1886. Since then it has remained the most common diagnosis for hospital admission requiring laparotomies. Approximately, $6 \%$ of the population will suffer from acute appendicitis during their lifetime; therefore, much effort has been directed toward early diagnosis and intervention. The human appendix had been proposed to be a vestigial structure, a structure that has lost all or most of its original function or that has evolved to take on a new function. The hypothesis was that it is the shrunken remnant of the cecum thought to have been present in a remote ancestor of humans. This theory is still widely held. Cecum, which occur in the digestive tracts of many herbivores (e.g. ox, horse), house mutualistic bacteria and ingested small stones that help animals digest the cellulose molecules found in plants. ${ }^{1}$

'Financial or Other Competing Interest': None.

Submission 19-09-2018, Peer Review 25-10-2018,

Acceptance 31-10-2018, Published 12-11-2018.

Corresponding Author:

Dr. Balaji Salunke,

General Surgeon, Department of General Surgery,

JNMC, Wardha, Maharashtra, India.

E-mail: balajisalunke04@gmail.com/dryrlamture@yahoo.co.in DOI: $10.14260 /$ jemds $/ 2018 / 1119$
Vermiform appendix is an element of the digestive tract which lies in right lower quadrant of abdomen, which has a worm-like structure and emerges during embryological life from the posteromedial wall of the cecum, about $2 \mathrm{~cm}$ below the ileocecal valve. The vermiform appendix is located in the right lower region of abdomen. Vermiform appendix is an element of the digestive tract, which lies in right lower quadrant of abdomen. Though, a remarkably constant structure in man, the appendix is nevertheless occasionally subject to the extremes of variation, that is total suppression and duplicity. Its length varies from 2 to $20 \mathrm{~cm}$, in average 9 $\mathrm{cm}$. Head of appendix can be placed in different situations, but the base of appendix is connected to the cecum. The variation in the situations is classified into six locations: retrocecal, pelvic, subcecal, paraileal, retroileal and subhepatic. The appendix contains lymph follicles. Lymphoid tissue first emerges in the appendix about 2 weeks after birth. Its epithelial lining has a surface coat of immunoglobulins, which may be involved in the control of lymphatic surveillance. Its epithelial lining has a surface coat of immunoglobulin, which may be involved in the control of lymphatic. The appendix develops from the midgut loop together with the caecum, ascending colon and the proximal two-thirds of the transverse colon. The appendix develops from the midgut loop together with the caecum, ascending colon and the proximal two-thirds of the transverse colon. 
Appendicitis is the main reason of acute abdomen in young people. Its opening is occasionally guarded by a semicircular fold of mucous membrane known as the valve of Gerlach. The appendix is usually located at the junction of the taeniae, found on the surface of the caecum. The attachment of the base of the appendix to the caecum remains constant, whereas the tip can be found in a retrocecal, pelvic, subcecal, preileal and postileal positions. It is connected by a short mesoappendix to the lower part of the ileal mesentery. This fold is usually triangular, extending almost to the appendicular tip along the whole tube. The mesoappendix has a free border which carries the blood supply to the organ, by the appendicular artery, a branch from the ileocolic artery. Appendicitis is the main reason of acute abdomen in young people. Identification of the normal position of appendix is important, because in appendicitis variable positions may produce symptoms and signs related to their position and hence can mimic other diseases. This study was conducted to study the variation in the anatomical features, length and external diameter of appendix and its association with age and sex in people in India. ${ }^{2}$

\section{MATERIALS AND METHODS}

This is a descriptive study of duration of 3 years. This study was conducted on total 418 cases of acute appendicitis. Operated for appendicectomy. Its anatomical location was recorded. Length of vermiform appendix was measured by nylon thread from root to tip of appendix. Thread's length was measured by vernier caliper. External diameter was measured by vernier caliper at a maximum external diameter of the appendix.

\section{RESULTS}

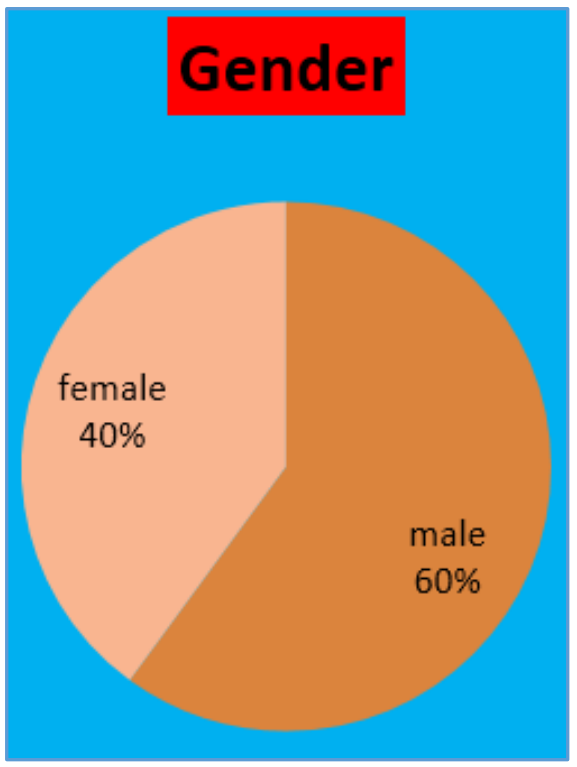

Figure 1. Gender

Males outnumber the females affected by acute appendicitis in the present study.

\begin{tabular}{|c|c|c|c|c|c|}
\hline Variable & Total & Mean & $\begin{array}{c}\text { Std. } \\
\text { Deviation }\end{array}$ & Minimum & Maximum \\
\hline Haemoglobin & 418 & 12.29 & 1.6 & 9.4 & 15 \\
\hline \multicolumn{5}{|c|}{ Table 1. Haemoglobin Level } \\
\hline
\end{tabular}

Out of 418 patients of acute appendicitis, haemoglobin level ranges from 9.4 to 15 with mean of 12.29 .

\begin{tabular}{|c|c|c|}
\hline Type of Incision & Frequency & Percentage \\
\hline McBurney's & 396 & 94.74 \\
\hline Right Paramedian & 22 & 5.26 \\
\hline Total & $\mathbf{4 1 8}$ & $\mathbf{1 0 0}$ \\
\hline \multicolumn{2}{|c|}{ Table 2. Type of Incision } \\
\hline
\end{tabular}

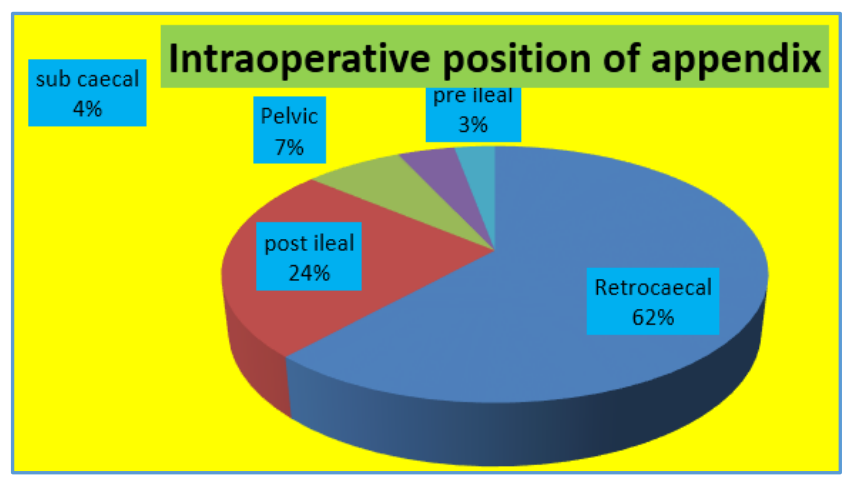

Figure 2. Intraoperative Position of Appendix, most common was Retrocecal in 258 Patients

\section{DISCUSSION}

Around 418 subjects were included in the study, consists of 251 (60.05) of males and 167 (39.95) from female gender (see Fig. 1). Clinically, diagnosed as acute appendicitis subjected for thorough clinical examination, lab investigations, USG abdomen and subjected appendiceal specimen for histopathological examination after surgery. Haemoglobin evaluated was in range of $9.4 \mathrm{gm} / \mathrm{dL}$ to 15 gm/dL with mean level of $12.29 / \mathrm{dL}$ (see Table No. 12). TLC was in range of 3300 to 20500 with mean level of 10450.28 (See Table 1).

All patients were operated by open appendicectomy method. In 396 (94.74\%) patients, McBurney's grid iron incision and in remaining 22 (5.26\%) patients right paramedian incision was taken to remove appendix (see Table No. 2).

The ultimate position of the appendix is profoundly influenced by the changes in position and shape, which the caecum undergoes during development and growth. The primordium of cecum and vermiform appendix, i.e. cecal diverticulum appears in the 6th week as a swelling on the antimesenteric border of the caudal limb of the midgut loop. After the completion of the gut rotation, the cecal diverticulum occupies a position on the right side of the abdominal cavity. ${ }^{2}$ In this study, the most common position of appendix was retrocecal and the lowest was subhepatic position.

According to many authors, the vermiform appendix is the only organ in the human body which has multiple definitive anatomical positions. Its position varies from individual-to-individual. The position of the vermiform appendix was of great interest, not only because of its evolutionary significance but also because of its pathological and surgical importance. Appendicitis was a common medical problem in man and woman at all ages from childhood to old age. The position of the organ was important in the clinical presentation, surgical approach and prognosis of the appendix related diseases. ${ }^{3}$ 
In the present study, we find various intraoperative positions of the appendix (Fig. 1). Most common position was retrocecal in 258 (61.72\%). In study done by Rahman et al $^{3}$ found pelvic as a commonest position in Bangladeshi people and retrocecal was second common position.

Jayasree et $\mathrm{al}^{4}$ in her study, the most common type of presentation of the appendix was found to be pelvic type in $50 \%$ of cadavers. The lowest presentation was preileal $7.1 \%$. Our study was in agreement with findings by other authors in the same area. In a study by Ajmani ML et al, 5 in a study in Uttar Pradesh (UP), India found the commonest presentation to be retrocecal. Sheela D Kadam et $\mathrm{al}^{6}$ in the Karad District of Maharashtra State in India found the most common presentation was pelvic $68.4 \%$. A study done by Chaudhary et al, mean age of individual was 38.7 years. The main finding of present study was that the appendix length and width were $8.52 \mathrm{~cm}$ and $1.21 \mathrm{~cm}$, respectively. The weight of the appendix ranges between 1 and 18 with an average of 6.43 grams. The retrocecal position of the appendix was highest $(71.7 \%)$ followed by pelvic $(14.7 \%)$ and retroileal $(6.5 \%)$, which was comparable with the similar study done by Ghorbani A et al. The most common position of appendix was retrocecal and the lowest was subhepatic position. This finding is correlated with the similar study done by L Ajmani et al in India, Ojeifo et al in Bosnia, Solanki TF et al in India, Cecil PG et al, Shah MA et al.

In Gray's Anatomy, it has been mentioned that the length of the appendix ranges between 2 and 20 with an average of 9 $\mathrm{cm}$. Most common position is retrocecal. ${ }^{7}$ Our findings are similar to the textbook's data, as mean length of the appendix ranged from $4 \mathrm{~cm}$ to $9 \mathrm{~cm}$.

In a study done by Ahmad Ghorbani et al, the most common position of appendix was pelvic position and the lowest was preileal position. Pelvic position was also found in studies of Katzurski et al, Ojeifo et al, Rahman et al and Paul et al. These findings were not similar to present study. However, there were similar findings in studies done by $\mathrm{L}$ Ajmani and $\mathrm{K}$ Ajmani in India, Ojeifo et al in Bosnia and CleggLamptey et al in Ghana have reported that the most common position of appendix is retrocecal and pelvic. It seems that many factors including race are involved in determining the position of the appendix.

Study of Ahmed et al, who have estimated the appendix size during therapeutic laparotomy. The most common position of appendix has been pelvic position in his study. Variable positions of vermiform appendix may have an effect on the diagnosis of appendicitis, which is one of the most common causes of acute abdomen. If the location of appendix was viewed in relation to the cecum, it can be divided into anterior (pelvic and pre- and retroileal) or posterior (retrocecal and paracecal) locations. The anterior location of appendix was seen in more than $75 \%$ of our studied population. So, early diagnosis of appendicitis and shorter duration of surgery and hospitalisation are expected among Iranian patients. This can reduce the complications of appendicitis surgery. ${ }^{8}$

A study done by Golalipour MJ et $\mathrm{al}^{9}{ }^{9}$ the incidence of pelvic position of appendix (33.3\%) was the highest accounting for $33.9 \%$ in males and $32.8 \%$ in females. His study determined the most common variety, length and mesentery of the appendix in this area. Therefore, it can help the surgeons to make optimal diagnosis and treatment of appendicitis. In $65.8 \%$ of the patients, the mesoappendix failed to reach the tip of the appendix, which was higher compared with $46.7 \%$ in Sudan (Bakheit and Warille, 1999). This condition in children (0 - 18 years) was $69 \%$ in his study; however, in another study (Bakheit and Warille, 1999) it was $87.7 \%$. Failure of the mesoappendix to reach the tip probably reduces the vascularisation of the tip of the organ, making it more liable to become gangrenous and hence early perforation during inflammation. This accounts for seriousness of the disease in children (Sabiston et al 2001, Schwartz et al 1999, Bakheit and Warille 1999). The observed differences noticed in the length, mesoextension and the variety of position in the appendix vermiform in native Fars and Turkmen races may be related to the racial factor, which needs further investigation to be proved. In conclusion this study determined the most common variety, length and mesentery of the appendix in this area. Therefore, it can help the surgeons to make optimal diagnosis and treatment of appendicitis. However, interesting findings of shortness of mesoappendix and smaller length of appendix in adults are unexplained and more investigations are recommended.

Appendix is the only organ in our body, which has no constant anatomical position. Various positions of vermiform appendix are useful to understand the location of site of occurrence of pain during appendicitis. Retrocecal appendix has symptoms of upper urinary tract infection due to irritation of the adjacent ureter. In pelvic position pain may be felt when the thigh is flexed and medially rotated, because the obturator internus is stretched. Pelvic appendix may irritate the bladder or rectum causing suprapubic pain, pain with urination or feeling the need to defecate. Postileal position in some males can irritate the ureter and cause testicular pain. In subhepatic position, the patient have pain in the right hypochondriac region. From various positions of vermiform appendix we can understand the possible outcome of the appendicitis, specifically location of site of pain. Appendix is supplied by end artery, which is one of the causes of occurrence of appendicitis. Appendicular artery, which is branch of inferior division of ileocolic artery goes through appendix along mesoappendix.

\section{CONCLUSION}

Appendix is the only organ in our body, which has no constant anatomical position. Knowledge regarding various positions of vermiform appendix is useful in understanding the site of occurrence of pain during appendicitis. Retrocecal appendix has symptoms of upper urinary tract infection due to irritation of the adjacent ureter. In pelvic position, pain may be felt when the thigh is flexed and medially rotated, because the obturator internus is stretched. Pelvic appendix may irritate the bladder or rectum causing suprapubic pain, pain with urination or feeling the need to defecate. Postileal position in some males can irritate the ureter and cause testicular pain. In subhepatic position, the patient may have pain in the right hypochondriac region. Appendix is supplied by end arteries which is one of the causes for occurrence of appendicitis. Appendicular artery which is the branch of inferior division of ileocolic artery goes through appendix along mesoappendix. Appendix has great variations in different races and communities. It was observed in this group of population that most common presentations were pelvic type. 


\section{REFERENCES}

[1] Al-Hashemy AM, Seleem MI. Appraisal of the modified Alvarado Score for acute appendicitis in adults. Saudi Medical Journal 2004;25(9):1229-31.

[2] Chaudhari ML, Kanani S. Anatomical variations of vermiform appendix in Gujarat. Int $\mathrm{J}$ Anat Res 2018;6(1.1):4815-8.

[3] Rahman MM, Khalil M, Rahman H, et al. Anatomical positions of vermiform appendix in Bangladeshi people. J Bangladesh Soc Physiol 2006;(1):5-9.

[4] Ch. Jayasree, Reddy CK. A study of anatomical positions of vermiform appendix in cadaver. J Cont Med A Dent 2018;6(1):64-7.

[5] Ajmani Ml, Ajmani K. The position, length and arterial supply of vermiform appendix. Anat Anz 1983;153(4):369-74.

[6] Sheela DK, Priya PR, Doshi MA, et al. Morphological variations of vermiform appendix and caecum: a cadaveric study. Int J Anat Res 2017;5(2.3):3983-7.
[7] Borley NR. Gray's anatomy: the anatomical basis of clinical practice. 39th edn. Edinburgh: Churchill Livingstone 2005: p. 1095-395.

[8] Ghorbani A, Forouzesh M, Kazemifar AM. Variation in anatomical position of vermiform appendix among Iranian population: an old issue which has not lost its importance. Hindawi Publishing Corporation, Anatomy Research International Article ID 313575, 2014;2014: p.

4. http://dx.doi.org/10.1155/2014/313575

[9] Golalipour MJ, Arya B, Azarhoosh R, et al. Anatomical variations of vermiform appendix in south-east Caspian sea (Gorgan-IRAN). J Anat Soc India 2003;52(2):141-3. 